\title{
A CMOS Bio-Impedance Measurement System
}

\author{
Alberto Yúfera and Adoración Rueda \\ Instituto de Microelectrónica de Sevilla (IMSE), Centro Nacional de Microelectrónica (CNM-CSIC) \\ Universidad de Sevilla \\ Av. Américo Vespucio s/n. 41092. Sevilla. SPAIN \\ Email:\{yufera,rueda\}@imse.cnm.es
}

\begin{abstract}
This paper proposes a new method for bio-impedance measurement useful to $2 \mathrm{D}$ processing of cell cultures. It allows to represent biological samples by using a new impedance sensing method, and exploiting the electrode-to-cell model for both electrical simulation and imaging reconstruction. Preliminary electrical simulations are reported to validate the proposal for Electrical Cell Impedance Spectroscopy (ECIS) applications. The results reported show that low concentration cell culture can be correctly sensed and displayed at several frequencies using the proposed CMOS system.
\end{abstract}

keywords -- Bioimpedance, biometric circuits, CMOS analog circuits, bio-instrumentation, sensory systems.

\section{INTRODUCTION}

$\mathrm{T}$ he impedance is an useful parameter for determining the properties of biological materials because these are conductives [1] and impedance measurement represents a noninvasive technique. Many biological parameters and processes can be sensed and monitored using its impedance as marker [25]. Impedance Spectroscopy of cell culture [6] and Electrical Impedance Tomography (EIT) in bodies [7] are two examples of the impedance utility for measuring biological and medical processes and parameters.

Classical imaging systems for biological samples are based on optical stimulation of samples demanding bulky and expensive equipments. Embedded CMOS sensor have been reported as an alternative to increase the sensitivity to cell location and manipulation. The most popular are optical [10], capacitive [8] and impedance [9] based sensors. In spite of the high number of works with optical sensor in last years, they still need external lamps, optical fibers, etc, while capacitive and impedance based detection do not rely on external equipment.

This paper proposes a new method for impedance measure with applications to cell culture imaging system. The system employs a two dimension electrode array acting as sensor $[11,12]$ together with CMOS circuits for impedance measure [13]. It allows the selection of input frequency to optimize the

This work is in part supported by the Spanish founded Project: TEC2007-68072/ TECATE, Técnicas para mejorar la calidad del test y las prestaciones del diseño en tecnologías CMOS submicrométricas. sensitivity of electrode sensors and to control, by design, the voltage applied to electrodes for their adequate polarization. The proposed system shown in Fig. 1 includes circuits for exciting and measuring the impedance of each electrode, for addressing rows and columns in the array, and can be fully-integrated in CMOS technologies. When low concentration cell cultures are carried out on top of an electrode array, depending on the position of each cell, a different electrode-cell impedance will be measured, allowing cell detection. Electrical models have been reported for the electrode-cell interfaces [12,14], being these key for matching electrical simulations to real systems performance and hence decoding correctly the results obtained experimentally, usually known as reconstruction problem.

This paper in organized as follows: in section II is described the area parametrized cell-electrode electrical model for both simulation and imaging reconstruction. Proposed CMOS system and circuits for impedance measure are reported in section III. Design system considerations and simulation results for an $8 \times 8$ electrode array are given in section IV. Conclusion are underlined in section $\mathrm{V}$.

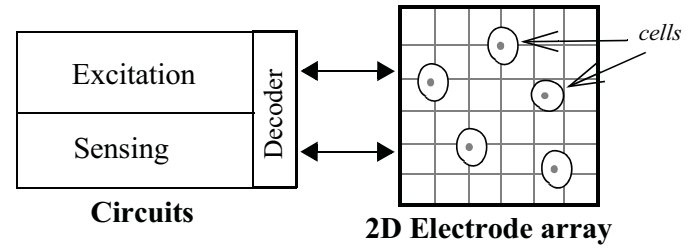

Fig.1. Proposed system for the 2D cell imaging system based on impedance sensing: circuits and two dimension electrode array with cell culture on top.

\section{THE CELL-Electrode Model}

An equivalent circuit for modelling the electrode-cell interface performance is a requisite for electrical characterization of the cells on top of electrodes. Fig. 2 illustrates a two-electrode sensor useful for ECIS technique [12]: $\mathrm{e}_{1}$ is called sensing electrode and $\mathrm{e}_{2}$ reference electrode. Electrodes can be fabricated in CMOS process in metal layers [11] or adding post-processing steps [12]. The sample on $\mathrm{e}_{1}$ top is a cell 
whose location must be detected. The circuit models developed to characterize electrode-cell interfaces [12,14] contain technology processes information and assume, as main parameter, the overlapping area between cells and electrodes. An adequate interpretation of these models gives information for: a) electrical simulations: parametrized models can be used to update the actual electrode circuit in terms of its overlapping with cells. b) imaging reconstruction: electrical signals measured on the sensor can be associated to a given overlapping area, obtaining the actual area covered on the electrode from measurements done.

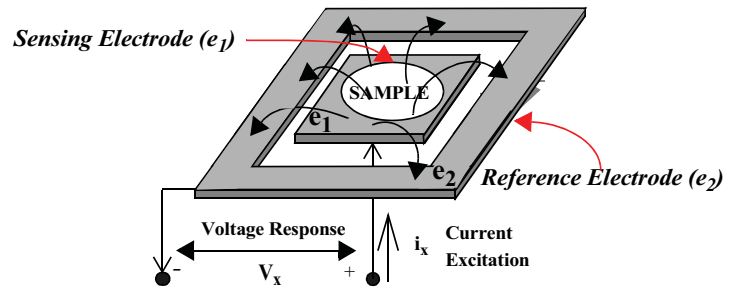

Fig.2. Basic concept for measuring in ECIS tecnique using two electrodes: $\mathrm{e}_{1}$ or sensing electrode and $\mathrm{e}_{2}$ or reference electrode. AC current $i_{x}$ is injected between $e_{1}$ and $e_{2}$, and voltage response $V_{x}$ is measure from $\mathrm{e}_{1}$ to $\mathrm{e}_{2}$, including effect of $\mathrm{e}_{1}, \mathrm{e}_{2}$ and sample impedances.

In this work, we selected the electrode-cell model reported in [12]. This model was obtained by using finite element method simulations, and considers the sensing surface of $\mathrm{e}_{1}$ could be total or partially filled by cells. Figure 3 shows this model. For the two-electrode sensor in Fig. 2, with $e_{1}$ sensing area $A, Z(\omega)$ is the impedance by unit area of the empty electrode (without cells on top). When $\mathrm{e}_{1}$ is partially covered by cells in a surface $A_{c}, Z(\omega) /\left(A-A_{c}\right)$ is the electrode impedance associated to noncovered area by cells, and $Z(\omega) / A_{c}$ is the impedance of the covered area. $\mathrm{R}_{\text {gap }}$ models the current flowing laterally in the electrode-cell interface, which depends on the electrode-cell distance at the interface (in the range of $10-100 \mathrm{~nm}$ ). $R_{\mathrm{S}}$ is the spreading resistance through the conductive solution. In this model, the signal path from $\mathrm{e}_{1}$ to $\mathrm{e}_{2}$ is divided into two parallel branches: one direct branch through the solution, not covered by cells, and a second path containing the electrode area covered by the cells. For the empty electrode, the impedance model $Z(\omega)$ has been chosen as the circuit illustrated in Fig. $3 c$, where $C_{p}, R_{p}$ and $\mathrm{R}_{\mathrm{s}}$ are dependent on both electrode and solution materials. Other cell-electrode models can be used [14], but for they the measure method here in proposed is still valid. We have considered for $\mathrm{e}_{2}$ the model in Fig 3a, not covered by cells. Usually reference electrode is common for all sensors, being its area much higher than $\mathrm{e}_{1}$. Figure 4 represents the impedance magnitude, $\mathrm{Z}_{\mathrm{xoc}}$, for the sensor system in Fig. 2, considering that $\mathrm{e}_{1}$ could be either empty, partially or totally covered by cells. The parameter ff is called fill factor, being zero for $\mathrm{A}_{\mathrm{c}}=0$ (electrode empty), and 1 (a)

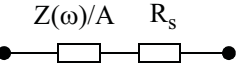

(b)

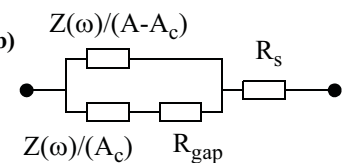

(c)

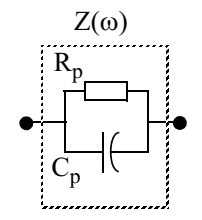

Fig.3. Model for (a) $e_{1}$ electrode without cells and (b) $e_{1}$ cellelectrode. (c) Model for $Z(\omega)$ used in this work.

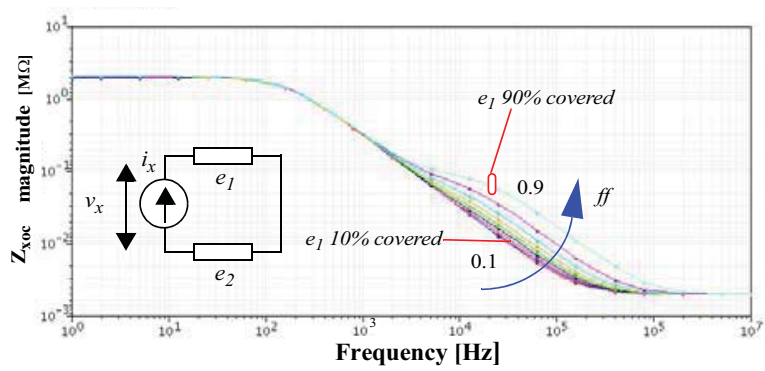

Fig.4. Sensor impedance magnitude as fill factor parameter ( ff) $\mathrm{C}_{\mathrm{p}}=1 \mathrm{nF}, \mathrm{R}_{\mathrm{p}}=1 \mathrm{M} \Omega, \mathrm{R}_{\mathrm{s}}=1 \mathrm{k} \Omega$ and $\mathrm{R}_{\mathrm{gap}}=100 \mathrm{k} \Omega$.

for $\mathrm{A}_{\mathrm{c}}=\mathrm{A}$ (electrode full). We define $\mathrm{Z}_{\mathrm{xoc}}(f f=0)=\mathrm{Z}_{\mathrm{xo}}$ as the impedance magnitude of the sensor without cells.

Absolute changes on impedance magnitude of $\mathrm{e}_{1}$ in series with $\mathrm{e}_{2}$ are detected in a $[10 \mathrm{kHz}, 100 \mathrm{kHz}]$ frequency range as a results of sensitivity to area covered on $\mathrm{e}_{1}$. Relative changes can inform more accurate from these variations by defining a new figure-of-merit called $r$ [12], or normalized impedance magnitude, by the equation,

$$
r=\frac{Z_{x o c}-Z_{x o}}{Z_{x o}}
$$

where $r$ represents changes of impedance magnitude for the twoelectrode with cells $\left(Z_{\mathrm{xoc}}\right)$ respect to others without them $\left(Z_{\mathrm{xo}}\right)$. The graphics of $r$ versus frequency is plotted in Fig. 5, for a cellto-electrode coverage $f f$ from 0.1 to 0.9 in steps of 0.1 . It can be identified again the frequency range where the sensitivity to cells is high, represented by $r$ increments. For a given frequency, it can be linked each value of the normalized impedance $r$ with its $f f$, being possible the cell detection and estimation of the covered area $\mathrm{A}_{\mathrm{c}}$. For imaging reconstruction, this work proposes a new CMOS system to measure $r$ parameter for a given frequency, and to detect the corresponding covering area on each electrode according to sensitivity in Fig 5. 


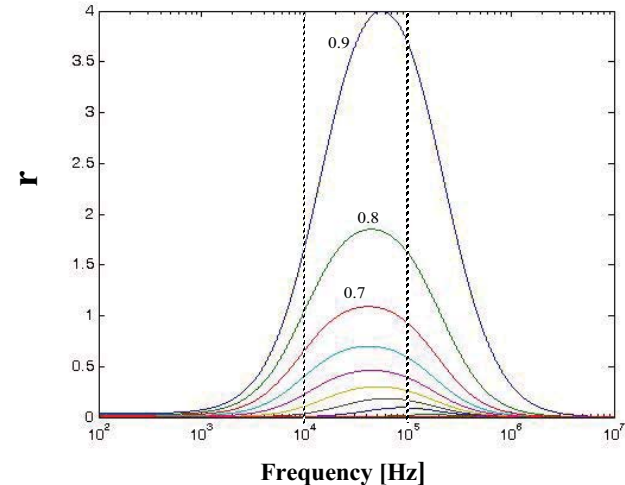

Fig.5. Normalized magnitude impedance $r$ for $f f=0.1$ to 0.9 in steps of 0.1

\section{IMPEDANCE MEASURE CIRCUITS}

New circuits required for sensing impedances have been implemented following the alternative feedback configuration in [13]. For the measure of impedance magnitude, $Z_{x o c}$, it will be considered that excitation signal is an AC current, with $\omega$ frequency. The circuits are designed to work maintaining a constant amplitude across the sensor $\left(\mathrm{V}_{\mathrm{xo}}=\mathrm{cte}\right)$, known as Pstat condition. The proposed circuit block diagram is shown in Fig. 6, and its main components are: the Instrumentation Amplifier (IA), the AC-to-DC converter or rectifier, the error amplifier, and the current oscillator with programmable output current. The voltage gain of the IA passband is $\alpha_{\mathrm{ia}}$. The rectifier works as a full wave peak-detector, to sense the biggest (lowest) voltage amplitude of $\mathrm{V}_{\mathrm{o}}$. Its output is a $\mathrm{DC}$ voltage, directly proportional to the amplitude of the instrumentation amplifier output voltage, with $\alpha_{\mathrm{dc}}$ gain. The error amplifier, with $\alpha_{\mathrm{ea}}$ gain, will compare the DC signal with a reference, $V_{\text {ref }}$, to amplify the difference. The voltage $V_{\text {ref }}$ represents the constant voltage level required to works in Pstat mode. The current oscillator generates the AC current to excite the sensor. It is composed by an external AC voltage source, $\mathrm{V}_{\mathrm{s}}$, an OTA with $\mathrm{g}_{\mathrm{m}}$ transconductance, and a four-quadrant voltage multiplier with $\mathrm{K}$ constant. The voltage generated by $\mathrm{V}_{\mathrm{s}}, \mathrm{V}_{\mathrm{so}} \cdot \sin \omega \mathrm{t}$, is multiplied by $\mathrm{V}_{\mathrm{m}}$, and then converted to a current by the OTA. The equivalent

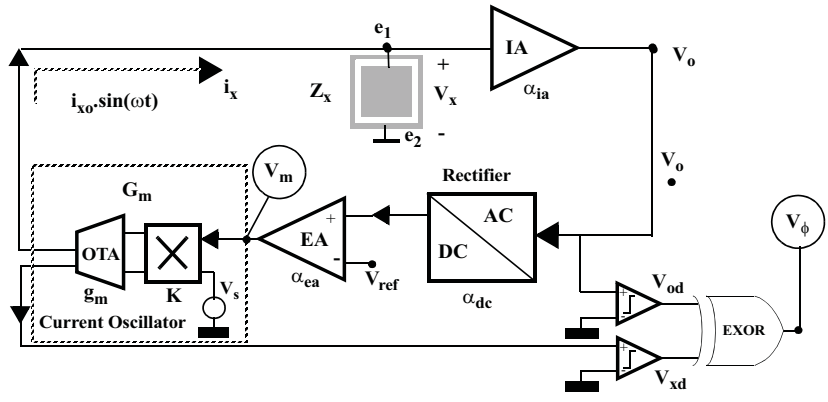

Fig.6. Circuit blocks for impedance sensing. transconductance from the magnitude voltage signal, $\mathrm{V}_{\mathrm{m}}$, to the excitation current, $i_{\mathrm{x}}$, is called $\mathrm{G}_{\mathrm{m}}$ and defined as $\mathrm{G}_{\mathrm{m}}=\mathrm{g}_{\mathrm{m}} \cdot \mathrm{V}_{\mathrm{so}} \cdot \mathrm{K}$. A simple analysis of the full system gives the approximated expression for the voltage amplitude at $\mathrm{V}_{\mathrm{x}}$,

$$
\mathrm{V}_{\mathrm{xo}} \approx \frac{\mathrm{V}_{\mathrm{ref}}}{\alpha_{\mathrm{ia}} \alpha_{\mathrm{dc}}}
$$

when condition,

$$
\mathrm{Z}_{\mathrm{xo}} \mathrm{G}_{\mathrm{m}} \alpha_{\mathrm{ea}} \alpha_{\mathrm{ia}} \alpha_{\mathrm{dc}} \gg 1
$$

is satisfied. Voltage in eq. (2) remains constant if $\alpha_{i a}$ and $\alpha_{d c}$ are also constant. Hence, Pstat condition is fulfilled if condition given before is true. On other hand, considering the relationship between the current $i_{x}$ and the voltage $V_{m}\left(i_{x o}=G_{m} \cdot V_{m}\right)$, the magnitude of the impedance can be expressed as,

$$
\mathrm{Z}_{\mathrm{xo}}=\frac{\mathrm{V}_{\mathrm{xo}}}{\mathrm{G}_{\mathrm{m}}} \cdot \frac{1}{\mathrm{~V}_{\mathrm{m}}}
$$

Equation (4) means that from voltage $V_{m}$, the impedance magnitude $Z_{x o}$ can be calculated, since $V_{x o}$ and $G_{m}$ are known from eq. (2) and the design parameters. The impedance phase could also be measure with $\mathrm{V}_{\phi}$ signal [13] in Fig. 6 . The circuits have been designed in a $0.35 \mu \mathrm{m}$ CMOS technology for $3 \mathrm{~V}$ power supply. Design parameters were adjusted for $10 \mathrm{kHz}$ frequency, with $Z_{\mathrm{xo}}=100 \mathrm{k} \Omega$. Parameters were chosen for $Z_{\mathrm{xo}} G_{\mathrm{m}} \alpha_{\mathrm{ia}} \alpha_{\mathrm{dc}} \alpha_{\mathrm{ea}}=100$. In particular, $\alpha_{\mathrm{ia}}=10, \alpha_{\mathrm{dc}}=0.25, \alpha_{\mathrm{ea}}=500$, $\mathrm{G}_{\mathrm{m}}=1.2 \mathrm{uS}$, and $\mathrm{V}_{\text {ref }}=20 \mathrm{mV}$.

The instrumentation amplifier circuit schematic [15] is represented in fig. 7a. The passband frequency edges were designed according with the frequency sensitivity observed in fig. 5. The frequency response, magnitude and phase, is illustrated in fig. $7 \mathrm{~b}$ for an input amplitude of $10 \mathrm{mV}$. The full wave rectifier in fig. $8 \mathrm{a}$ is based on pass transistors (MP, MN) to load the capacitor $\mathrm{C}_{\mathrm{r}}$ at the nearest voltage to $\alpha_{\mathrm{ia}} \mathrm{V}_{\mathrm{o}}$ [16]. The two comparators detect if the input signal is higher (lower) than $\mathrm{V}_{\text {op }}\left(\mathrm{V}_{\mathrm{om}}\right)$ in order to charge the $\mathrm{C}_{\mathrm{r}}$ capacitors. Discharge process of $\mathrm{C}_{\mathrm{r}}$ is done by current sources, $\mathrm{I}_{\mathrm{dis}}$, and has been set to $1 \mathrm{mV}$ in a period. Figure $8 \mathrm{~b}$ illustrates the waveforms obtained by electrical simulations for the upper and lower rectified signals at $10 \mathrm{kHz}$. A two-stage open loop operational amplifier is used as error amplifier. For $i_{\mathrm{x}}$ amplitude programming, a four-quadrant multiplier [17] and an OTA were designed. The multiplier output waveforms $\left(\mathrm{V}_{\mathrm{m}} \mathrm{x} \mathrm{V}_{\mathrm{s}}\right)$ are shown in fig. 9. In this figure, the $\mathrm{AC}$ signal $\mathrm{V}_{\mathrm{s}}$, has $200 \mathrm{mV}$ of amplitude at $10 \mathrm{kHz}$ frequency, is multiplied by a DC signal, $V_{m}$, in the range of $[0,200 \mathrm{mV}]$. Finally, with data employed, $V_{x}$ has an amplitude of $8 \mathrm{mV}$. In electrode based measures, $V_{\mathrm{xo}}$ has typically low and limited values (tens of $\mathrm{mV}$ ) to control the expected electrical performance of the electrodes [11]. 

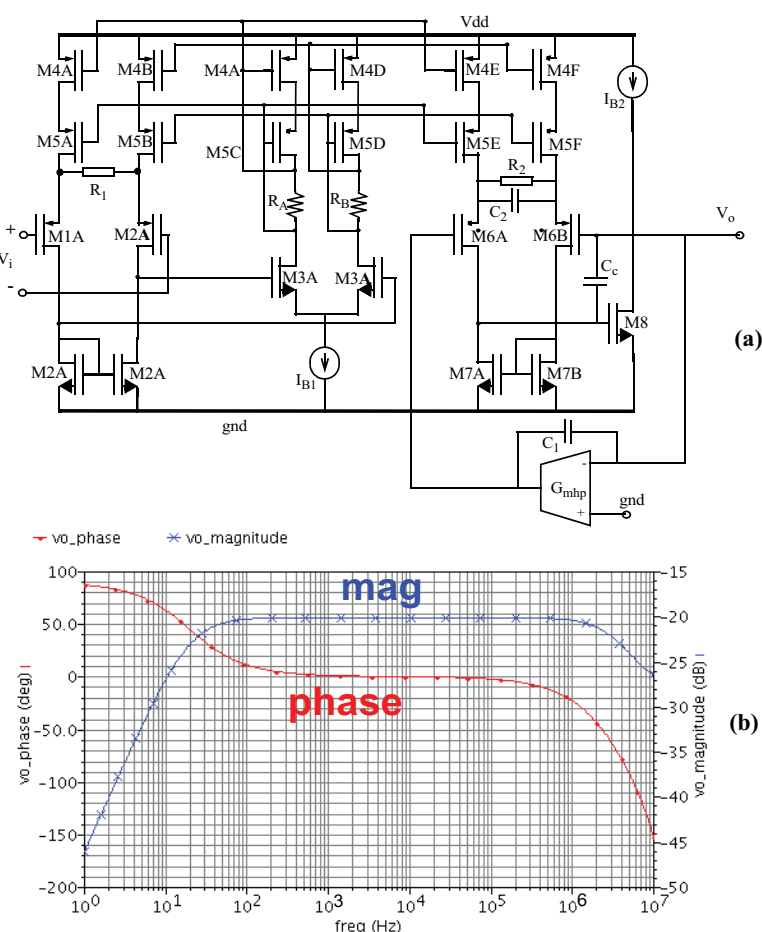

Fig.7. (a) CMOS Instrumentation Amplifier schematic. (b) Magnitude and phase frequency response for $10 \mathrm{mV}$ amplitude at the input.

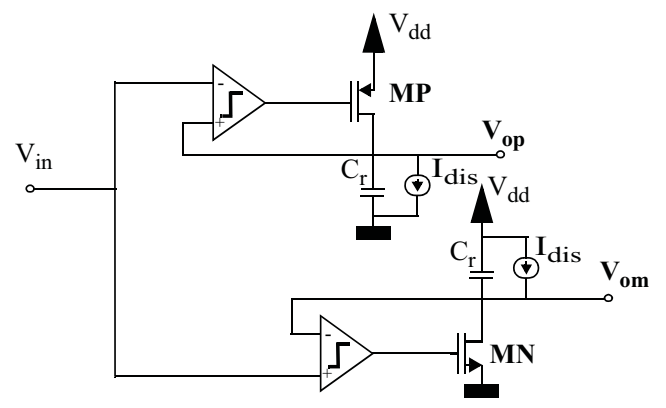

(a)

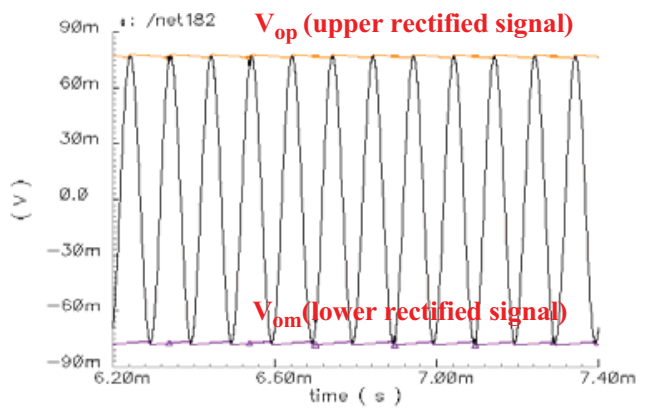

(b)

Fig.8. (a) Schematic for the full-wave rectifier. (b) Electrical simulations at $10 \mathrm{kHz}$.

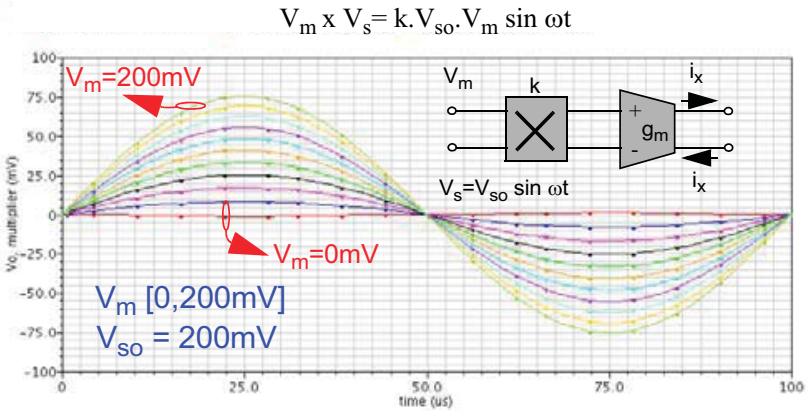

Fig.9. Simulated multiplier output voltage waveforms. The delivered AC current to electrodes $\left(i_{\mathrm{x}}\right)$ has an amplitude given by $\mathrm{i}_{\mathrm{xo}}=(\mathrm{k}$ $\left.\mathrm{g}_{\mathrm{m}} \mathrm{V}_{\mathrm{so}}\right) \cdot \mathrm{V}_{\mathrm{m}}$, in which can be considered $\mathrm{G}_{\mathrm{m}}=\mathrm{k} \mathrm{g}_{\mathrm{m}} \mathrm{V}_{\mathrm{so}}$ as the equivalent tranconductance from $\mathrm{V}_{\mathrm{m}}$ input voltage to $\mathrm{i}_{\mathrm{x}}$ output current. The amplitude of $i_{x}$ can be programmed with the $V_{m}$ voltage.

\section{Simulation Results}

To proof the proposed method for impedance sensing, we have chosen a simulation case with an $8 \times 8$ two-electrode array. The sample input to be analysed is a low density MCF-7 epithelial breast cancer cell culture shown in Fig. 10a. In this image, some areas are covered by cells and others are empty. Our objective is to employ the area parametrized electrode-cell model and the proposed circuits to detect their location. The selected pixel size is $50 \mu \mathrm{m} \times 50 \mu \mathrm{m}$, similar to cell dimensions. Figure 10a shows the grid and overlap with the image. We associate a squared impedance sensor to each pixel in Fig. 10a, To obtain a 2D system description valid for electrical simulation. Optimum pixel size can be obtained by using design curves for normalized impedance $r$ and its frequency dependence. Each electrical circuit associated to each $\mathrm{e}_{1}$ electrode in the array was initialized with its corresponding fill factor $(f f)$. Matrix in Fig $10 \mathrm{~b}$ is obtained in this way. Each electrode or pixel has associated a number in the range $[0,1](f f)$ depending on its overlap with cells on top. These numbers were calculated with an

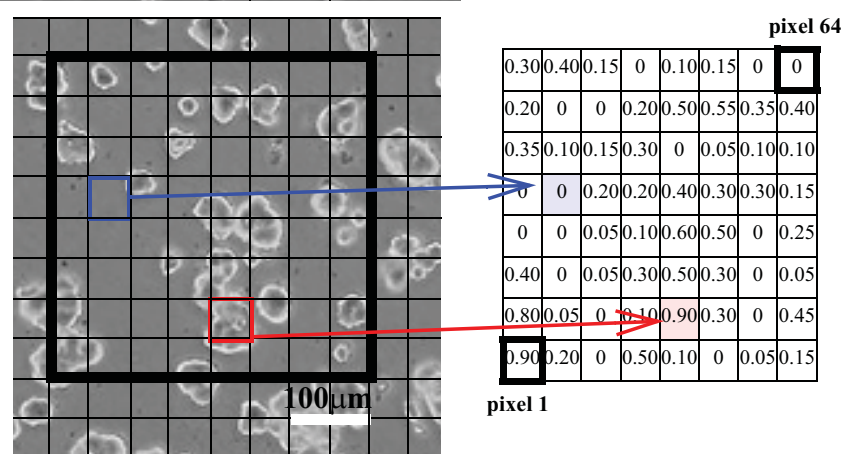

(a)

(b)

Fig.10. (a) $8 \times 8$ pixel area selection in ephitelial breast cancer cell culture. (b) Fill factor map (ff) associated to each electrode (pixel). 
accuracy of \pm 0.05 from the image in Fig.10a. The $f f$ matrix represents the input of our system to be simulated. Electrical simulations of the full system were performed at $10 \mathrm{kHz}$ (midband of the IA) to obtain the value of the voltage magnitude $\mathrm{V}_{\mathrm{m}}$ in eq. (4) for all electrodes. Pixels are simulated by rows, starting from the left most down (pixel 1) to top most right (pixel 64). When measuring each pixel, $\mathrm{V}_{\mathrm{m}}$ is reset to zero and then 25 cycles $\left(\mathrm{N}_{\mathrm{c}}\right)$ are reserved to find its steady-state, where $\mathrm{V}_{\mathrm{m}}$ value becomes constant and is acquired. In Fig. 12 are represented the waveforms obtained for the amplifier output voltage $\alpha_{i a} V_{x}$, voltage magnitude, $\mathrm{V}_{\mathrm{m}}$, and excitation current $\mathrm{i}_{\mathrm{x}}$. It is observed that the voltage at sensor, $\mathrm{V}_{\mathrm{x}}$, has always the same amplitude $(8 \mathrm{mV})$, while the current decreases with $f f$. The $\mathrm{V}_{\mathrm{m}}$ signal converges towards a DC value, inversely proportional to the impedance magnitude. Steady-stated values of $\mathrm{V}_{\mathrm{m}}$ are represented in Fig. 11 for all pixels. These are used to calculate their normalized impedances $r$ using eqs. (1) and (4).

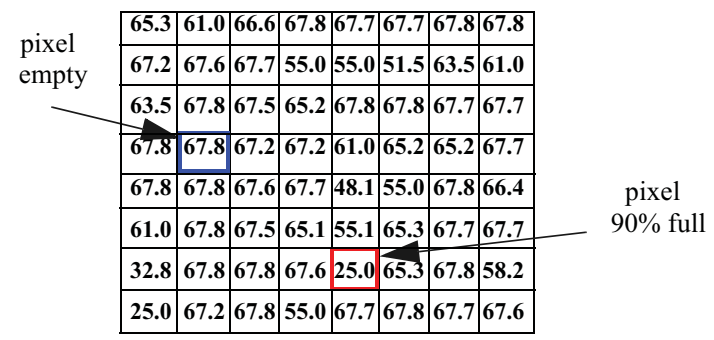

Fig.11. Simulated $\mathrm{V}_{\mathrm{m}}[\mathrm{mV}]$ steady-state values at $10 \mathrm{kHz}$ frequency.

To have a graphical 2D image of the fill factor (covered area by cells) in all pixels, Fig. 13 represents the $8 \times 8 \mathrm{ff}$-maps, in which each pixel has a grey level depending of its fill factor value (white is empty and black full). In particular, Fig. 13a represents the ff-map for the input image in Fig. 10a. Considering the parametrized curves in Fig. 5 at $10 \mathrm{kHz}$ frequency, fill factor parameter has been calculated for each electrode, using $\mathrm{V}_{\mathrm{m}}$ simulated data from Fig. 11 and the results are represented in Fig. 13b. The same simulations have been performed at $100 \mathrm{kHz}$, achieving the ff-map in Fig. 13c. As Fig. 5 predicts, better matching with input is found at $100 \mathrm{kHz}$ because normalized impedance is more sensitive, having higher
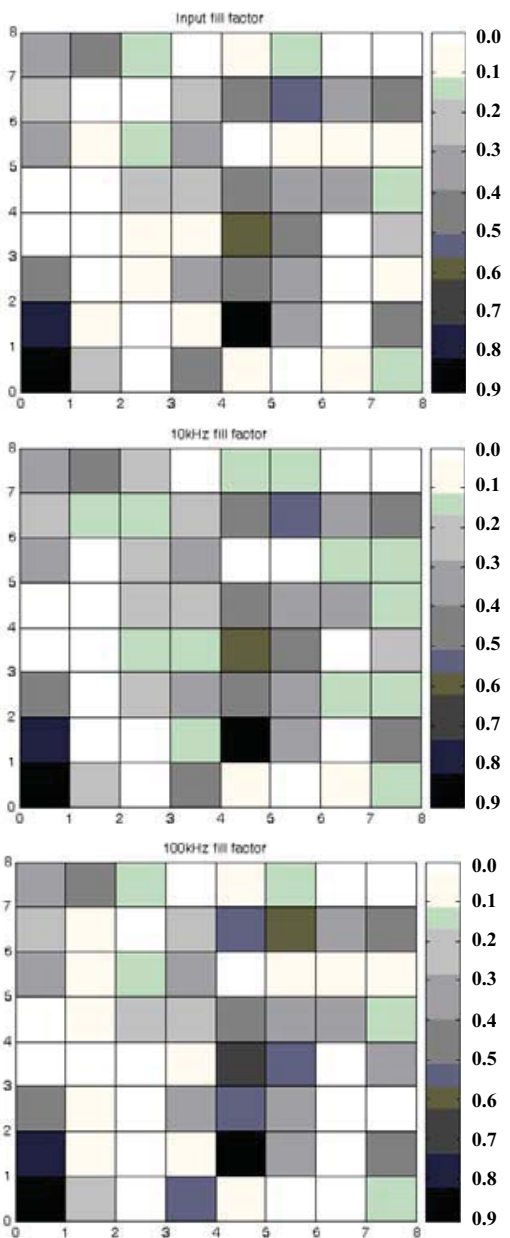

Input

(a)

Output at $10 \mathrm{kHz}$

(b)

Output at

$100 \mathrm{kHz}$

(c)

Fig.13. 2D diagram of the fill factor for $8 \times 8$ pixels: (a) ideal input, (b) image reconstructed from simulations at $10 \mathrm{kHz}$ and (c) from simulations at $100 \mathrm{kHz}$.
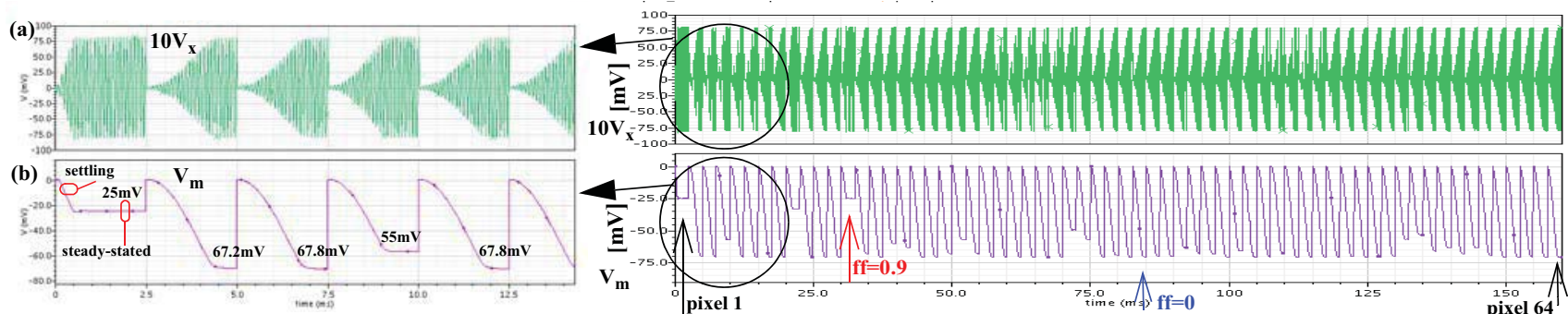

$10 \mathrm{~V}_{\mathrm{x}^{-}}$
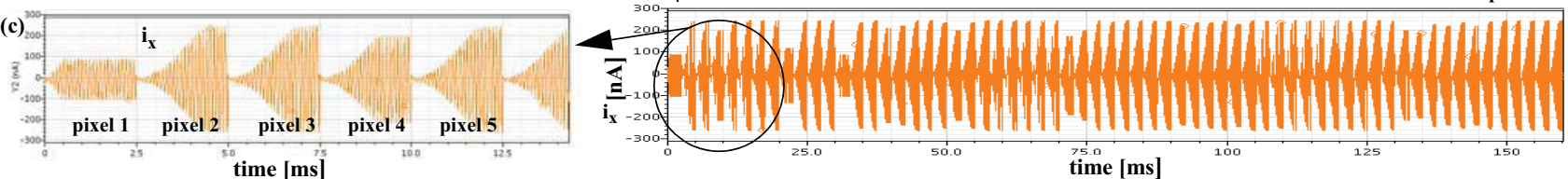

Fig.12. Simulated waveforms for (a) $\alpha_{i a} V_{x}=10 V_{x}$, (b) $V_{m}$ and (c) $i_{x}$ signals for the 64 electrodes at $10 \mathrm{kHz}$. 
dynamic range than at $10 \mathrm{kHz}$. In both cases, errors obtained in $f f$ values are below the $1 \%$, so matching with input is excellent. The total time required to acquired data for a full image or frame will depend on measuring frequency, number of cycles reserve for each pixel $\left(\mathrm{N}_{\mathrm{c}}=25\right.$ for reported example) and array dimension (8x8). For reported simulations, $160 \mathrm{~ms}$ and $16 \mathrm{~ms}$ for frame, working at $10 \mathrm{kHz}$ and $100 \mathrm{kHz}$ respectively, are required. This acquisition time by frame is enough for real time monitoring of cell culture systems.

\section{CONCLUSIONS}

This paper presents a novel system for impedance sensing of biological samples useful for 2D imaging. An electrical model based on the overlapping area is employed for electrode-cell characterization in both system simulation and image reconstruction. The proposed system works using Pstat approach and employs new circuit configuration for impedance measure in a feedback configuration, delivering easy to acquire signals and allowing to control the voltage amplitude on the electrodes. Electrical simulations have been done to reproduce ECIS technique, giving promising results in cell location and imaging, and enabling our system for other real time applications as cell index monitoring, cell tracking, etc. In future works, precise cell electrode model, optimized sensing circuits and design trade-off for electrode sizing will be further explored for a real experimental imaging system.

\section{REFERENCES}

[1] J. J. Ackmann, "Complex Bioelectric Impedance Measurement System for the Frequency Range from $5 \mathrm{~Hz}$ to $1 \mathrm{MHz}$," Annals of Biomedical Engineering, vol 21, pp:135-146, 1993.

[2] R. D. Beach, et al., "Towards a Miniature In Vivo Telemetry Monitoring System Dynamically Configurable as a Potentiostat or Galvanostat for Two- and Three- Electrode Biosensors," IEEE Transactions on Instrumentation and Measurement, vol 54, $\mathrm{n}^{\circ} 1$, pp:61-72, 2005.

[3] A. Yúfera et al.,"A Tissue Impedance Measurement Chip for Myocardial Ischemia Detection". IEEE transaction on Circuits and Systems: Part I. vol.52, $\mathrm{n}^{\mathrm{o}}: 12$, pp:2620-2628. Dec. 2005.

[4] S. M. Radke and E. C. Alocilja, "Design and Fabrication of a Microimpedance Biosensor for Bacterial Detection," IEEE Sensor Journal, vol 4, n 4, pp: 434-440, Aug. 2004.

[5] D. A. Borkholder: "Cell-Based Biosensors Using Microelectrodes," $P h D$ Thesis, Stanford University. Nov. 1998.

[6] I. Giaever et al., "Use of Electric Fields to Monitor the Dynamical Aspect of Cell Behaviour in Tissue Culture," IEEE Transaction on Biomedical Engineering, vol BME-33, nº 2, pp: 242-247, Feb. 1986.

[7] D. Holder, "Electrical Impedance Tomoghaphy: Methods, History and Applications", Philadelphia: IOP, 2005.

[8] A. Romani et al.," Capacitive Sensor Array for Location of Bioparticles in CMOS Lab-on-a-Chip," International Solid Stated Circuits Conference (ISSCC), 12.4. 2004.

[9] G. Medoro et al.,"A Lab-on-a-Chip for Cell Detection and Manipulation,". IEEE Sensor Journal, vol. 3, nº 3, pp: 317-325. Jun. 2003.
[10] N. Manaresi et al, "A CMOS Chip for individual Cell MAnipulation and Detection," IEEE Journal of Solid Stated Circuits, vol. 38, n 12, pp: $2297-$ 2305. Dec. 2003.

[11] A. Hassibi et al.:"A Programmable 0.18 $\mu \mathrm{m}$ CMOS Electrochemical Sensor Microarray for Biomolecular Detection," IEEE Sensor Journal, vol. 6, n ${ }^{\circ}$, pp:1380-1388. 2006.

[12] X.Huang et al.,"Simulation of Microelectrode Impedance Changes Due to Cell Growth," IEEE Sensors Journal, vol.4, n5, pp: 576-583. 2004.

[13] A. Yúfera et al., "A Method for Bioimpedance Measure With Four- and Two-Electrode Sensor Systems," 30th Annual International IEEE EMBS Conference, pp: 2318-2321. Aug. 2008.

[14] Neil Joye, et al.,"An Electrical Model of the Cell-Electrode Interface for High-density Microelectrode Arrays," 30th Annual International IEEE EMBS Conference, pp: 559-562. 2008

[15] Y-Q. Zhao et al., "A CMOS Instrumentation Amplifier for Wideband Bioimpedance Spectroscopy Systems," International Symposium on Circuits and Systems, ISCAS, pp:5079-5082. 2006.

[16] H. Ahmadi et al., "A Full CMOS Voltage Regulating Circuit for Bioimplantable Applications," International Symposium on Circuits and Systems, ISCAS, pp: 988-991, 2005.

[17] C. Sawing et al.,"Compact low-voltage CMOS four-quadrant analogue multiplier," Electronics Letters, vol.42, n² 20, pp: Sep. 2006 